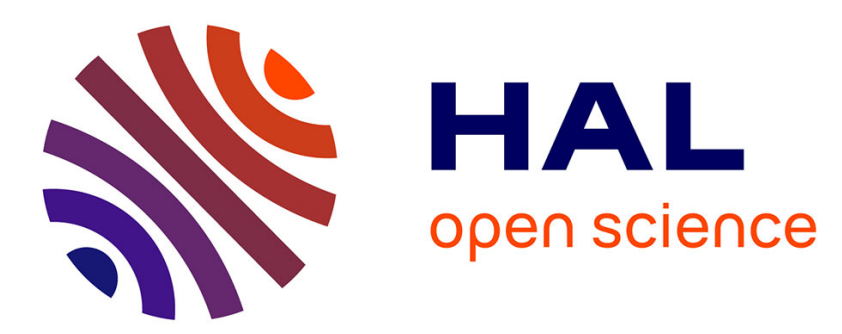

\title{
Isotopic effect on the ionization probabilities in secondary ion emission
}

\author{
G. Slodzian, J.C. Lorin, A. Havette
}

\section{To cite this version:}

G. Slodzian, J.C. Lorin, A. Havette. Isotopic effect on the ionization probabilities in secondary ion emission. Journal de Physique Lettres, 1980, 41 (23), pp.555-558. 10.1051/jphyslet:019800041023055500 . jpa-00231845

HAL Id: jpa-00231845

https://hal.science/jpa-00231845

Submitted on 1 Jan 1980

HAL is a multi-disciplinary open access archive for the deposit and dissemination of scientific research documents, whether they are published or not. The documents may come from teaching and research institutions in France or abroad, or from public or private research centers.
L'archive ouverte pluridisciplinaire HAL, est destinée au dépôt et à la diffusion de documents scientifiques de niveau recherche, publiés ou non, émanant des établissements d'enseignement et de recherche français ou étrangers, des laboratoires publics ou privés. 


\title{
Isotopic effect on the ionization probabilities in secondary ion emission $\left(^{\dagger}\right)$
}

\author{
G. Slodzian $(*)$ J. C. Lorin $\left({ }^{* *}\right)$ and A. Havette $(* * *)$ \\ $\left(^{*}\right)$ Laboratoire de Physique des Solides, Bât. 510, Université de Paris-Sud, 91405 Orsay, France \\ (**) Laboratoire de Minéralogie-Cristallographie, Tour 16, 4, place Jussieu, Université Paris VI, 75005 Paris, France \\ $\left({ }^{* * *}\right)$ Laboratoire de Pétrographie-Volcanologie, Bât. 504, Université de Paris-Sud, 91405 Orsay, France
}

(Reçu le 17 juillet 1980, accepté le 8 octobre 1980)

\begin{abstract}
Résumé. - On montre que les rendements d'ionisation sont légèrement différents d'un isotope à l'autre. Les corrélations observées entre la forme des distributions énergétiques, la valeur des rendements d'ionisation et la composition élémentaire de la cible sont expliquées à l'aide d'un modèle de rupture de liaison.
\end{abstract}

\begin{abstract}
It is shown that there are slight differences in the ionization yields of isotopes. The correlations observed between the shape of the energy distribution curves, the magnitude of ionization yields and the elemental composition of the sample are explained within the framework of a bond breaking model.
\end{abstract}

Secondary ions sputtered from a solid sample are characteristic of the chemical and isotopic composition of the target being bombarded. But it is known that ionization probabilities are under the influence of the elemental composition of the sample [1], which makes the quantitative determination of the elemental composition more complicated. It seemed that the measurement of the isotopic abundance ratios might escape these difficulties though deviations from standard values have been sometimes observed; indeed, one still could hope that these discrepancies were caused by artefacts like polyatomic ions or by instrumental discriminations.

In this paper, we show that there are actually differences in ionization yields between isotopes and we propose a model to explain this effect.

1. Experimental conditions. - Measurements were performed on a CAMECA IMS 300 microanalyser, on which several modifications have been made in order to improve the stability of the instrument, to increase the mass resolving power $(M / \delta M$ up to 5000 ) and to attach a transfer optical system [2]. The target was bombarded with $\mathrm{O}_{2}^{+}$ions of $5.5 \mathrm{keV}$ energy, and the density of the primary ion beam was adjusted so as to minimize the electrical charging-up on insu-

(†) La version française de cet article a été soumise pour publication aux Comptes Rendus de l'Académie des Sciences. lating samples. In the neighbourhood of each of the isotopes under study, a mass spectrum was recorded at high mass resolution in order to determine the best experimental procedure to be used for eliminating mass interferences. In some cases, when mass separation was not possible, the (very weak) contribution of interfering ions was deducted by the peak-stripping technique; for instance on the ${ }^{44} \mathrm{Ca}^{+}$peak, it was sometimes necessary to deduct a weak contribution of ${ }^{88} \mathrm{Sr}^{++}$which was estimated from the height of ${ }^{87} \mathrm{Sr}^{++}$being measured. The transfer optical system was adjusted so as to optimize the collection efficiency on a sample area of $25 \mu \mathrm{m}$ in diameter. Secondary ion currents were measured by a counting technique, the dead time of the electron-multiplier being taken into account. The precision (standard deviation divided by the mean value) on the ratios being measured depends on the counting statistics and on the overall stability of the instrument ; it varies from $0.3 \%$ to $2 \%$ according to the actual concentrations, when secondary ions collected in an energy interval $0-20 \mathrm{eV}$ were used.

2. Results. - For two isotopes whose atomic masses are $M_{\mathrm{i}}$ and $M_{\mathrm{j}}, R_{\mathrm{ij}}$ is defined as the ratio $N\left(\mathrm{M}_{\mathrm{i}}^{+}\right) / N\left(\mathrm{M}_{\mathrm{j}}^{+}\right)$of the number of ions counted with the multiplier for each isotope respectively. Let $R_{\mathrm{ij}}^{0}$ be the standard abundance ratio of these isotopes, the relative deviation is then given by $\Delta_{\mathrm{ij}}=\left(R_{\mathrm{ij}} / R_{\mathrm{ij}}^{0}-1\right)$; for 
comparing elements it is convenient to use the ratio $\alpha=\Delta_{\mathrm{ij}} /\left(\delta M_{\mathrm{ij}} / M_{\mathrm{j}}\right)$ where $\delta M_{\mathrm{ij}}=M_{\mathrm{i}}-M_{\mathrm{j}}$ with $M_{\mathrm{i}}>M_{\mathrm{j}}$. The measurements were made on terrestrial mineral samples and on elements like $\mathrm{Mg}, \mathrm{Si}, \mathrm{Ca}$ known to be practically unfractionated in geochemical processes $[3,4,5]$. It can be seen (Fig. 1) that the variation of $\Delta_{\mathrm{ij}}$ against $\delta \boldsymbol{M}_{\mathrm{ij}} / \boldsymbol{M}_{\mathrm{j}}$ is practically linear.

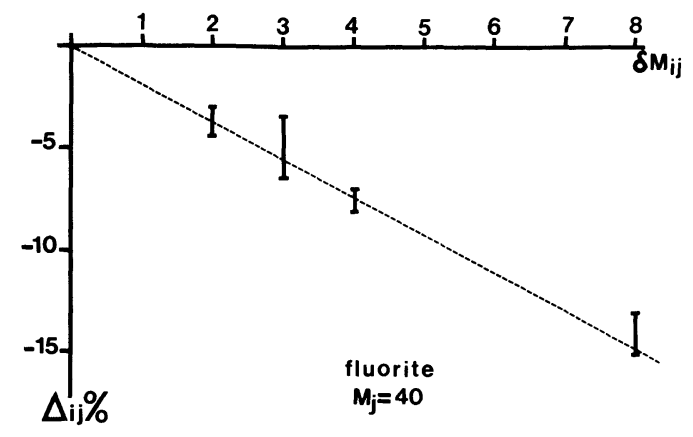

Fig. 1. - Relative deviations of the measured $\mathrm{Ca}$ isotopic ratios from the actual values. $\delta M_{\mathrm{ij}}$ is the mass difference with respect to the reference isotope, ${ }^{40} \mathrm{Ca}$.

Besides, our observations lead us to a sign of $\alpha$ which was always negative. Another feature is shown on figure 2, that is the increase of $\Delta_{\mathrm{ij}}$ with the energy $E_{0}$ of secondary ions. In addition, for a given element, there is a definite correlation between the amplitude of $\alpha$, the shape of the energy distribution curve and the ionization yield $\tau$ (number of $\mathrm{M}^{+}$ions being collected into a given solid angle and energy interval per $M$

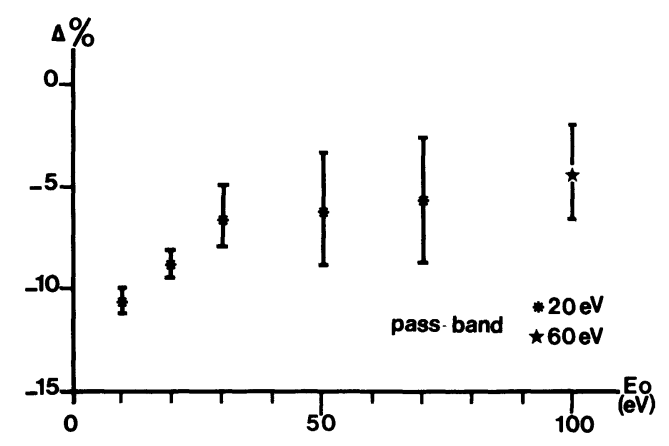

Fig. 2. $-\Delta=\left[\left({ }^{30} \mathrm{Si} /{ }^{28} \mathrm{Si}\right)_{n} /\left({ }^{30} \mathrm{Si} /{ }^{28} \mathrm{Si}\right)_{0}\right]-1$; olivine sample.

atom present in the sputtered volume). For instance, the comparison between the energy distributions of $\mathrm{Ca}^{+}$ions (Fig. 3) shows that on a calcite sample there is a lower proportion of slow ions than on a feldspar; simultaneously, it is observed that $\tau$ is five times lower on a calcite than on a feldspar sample and that the isotopic effect as typified by $\alpha$ is respectively -0.8 and -0.04 . Similar results were obtained on silicon. One should also note that on a given sample the $\alpha$ values may vary with the nature of the elements (Fig. 5).

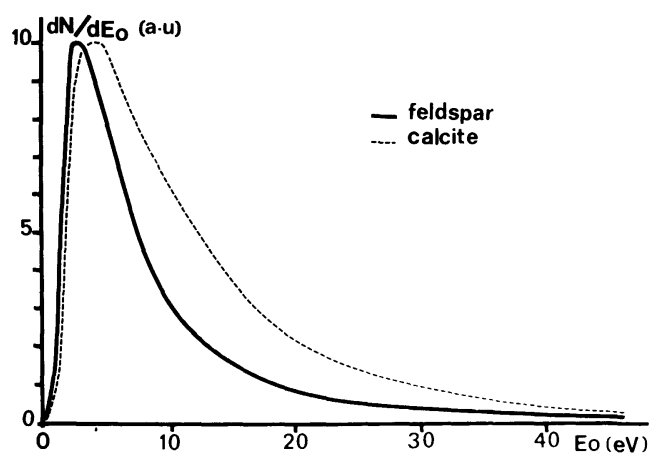

Fig. 3. - Energy spectrum of ${ }^{40} \mathrm{Ca}^{+}$ions normalized to the maximum of the energy distribution in feldspar and calcite (energy window : $1 \mathrm{eV})$.

3. Discussion. - It should be emphasized that if the quantum efficiency of the multiplier were dependent on the mass of the isotopes, the values of $\Delta_{i j}$ would exhibit systematic errors. The existence of a matrix effect on the isotopic deviation tends to prove that the effect on quantum efficiency is of little importance in our experiments and, to a first approximation and taking into account the limited precision of the measurements, it can be neglected. However, it is a point that remains to be verified carefully.

The phenomena involved in sputtering processes are such that the difference in behaviour of two isotopes can be only related to their difference in masses. Let us examine how the ionization probabilities may depend on a mass difference. It is known that most of the sputtered atoms are ejected from the first atomic layer; for the sake of simplicity, let us consider only the last collision, that is to the collision which occurs between a $\mathrm{B}$ atom of the target, belonging to the atomic collision cascade triggered off by the impact of the primary ion, and a $\mathbf{M}_{\mathrm{i}}$ atom (mass $m_{\mathrm{i}}$ ) in the surface layer. Now let us assume that the process occurs in two steps : in the first one, the collision sets $\mathrm{M}_{\mathrm{i}}$ in motion (possibly, it could also bring $\mathrm{M}_{\mathrm{i}}$ into an excited state); in the second one, $\mathrm{M}_{\mathrm{i}}$ is ionized as it exits according to a process somewhat similar to the dissociation of a diatomic molecule as described by the Landau-Zener-Stueckelberg model [6]. This model leads to a probability of ionization $P=\exp \left(-a / v_{\mathrm{c}}\right)$ where $v_{\mathrm{c}}$ is the relative velocity of the atomic partners $M_{i}$ and $B$ - in the frame of reference of their centre of mass - at the intersection point $\mathrm{C}$ of the potential curves corresponding to covalent and ionic bonds respectively (Fig. 4) and where $a$ is a parameter which depends on the slopes of the curves at their crossing point $\mathrm{C}$ and on the energy gap appearing when the degeneracy is removed (anticrossing). The relative deviation $\Delta$ for two isotopes struck under the same initial conditions by $\mathrm{B}$ is given by $\Delta \simeq a\left(\delta v_{\mathrm{c}} / v_{\mathrm{c}}^{2}\right)$. If the model were directly applied to the collisions of $B$ on $\mathrm{M}_{\mathrm{i}}$ and of $\mathrm{B}$ on $\mathrm{M}_{\mathrm{j}}$, one would get a positive value for $\Delta_{\mathrm{ij}}$ because the collisions being inelastic, other 


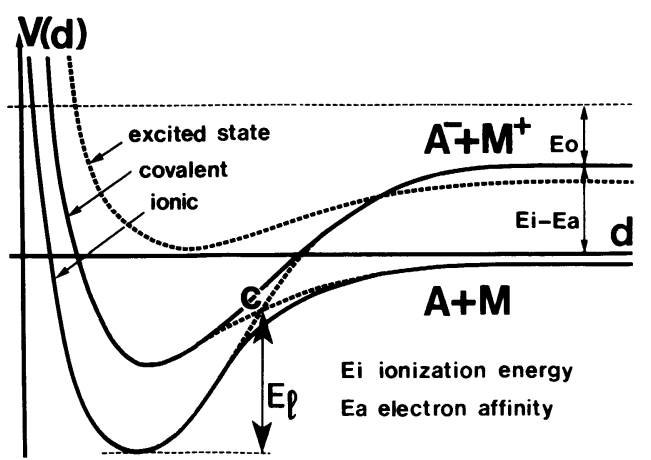

Fig. 4. - Anticrossing diagram; $d$ is the distance between $\mathrm{A}$ and $\mathrm{M}$, $E_{0}$ the kinetic energy of the secondary ion $\mathrm{M}^{+}, E_{\mathrm{i}}$ the ionization energy of the element $M, E_{\mathrm{a}}$ the electron affinity of $\mathrm{A}$ and $E_{1}$ the energy expended to reach point $C$. The distance between the two horizontal dotted straight lines measures the energy given to $\mathbf{M}$ in the last collision.

things being equal, the heavier the isotope, the larger the relative velocity $v_{\mathrm{c}}$. On the contrary, $v_{\mathrm{c}}$ represents the velocity of $M_{i}$ relative to the target's frame of reference if one assumes that, in the second step, the dissociation occurs between $\mathbf{M}_{\mathbf{i}}$ and an anionic group $\mathrm{A}$ tied to the target (and, for instance, composed of fixed neighbouring oxygen atoms and the $\mathrm{B}$ cation). In the case of two isotopes $\mathrm{M}_{\mathrm{i}}$ and $\mathrm{M}_{\mathrm{j}}$, the relative variation $\delta v_{\mathrm{c}} / v_{\mathrm{c}}$ can be expressed as

$$
\delta v_{\mathrm{c}} / v_{\mathrm{c}} \simeq K\left(\delta M_{\mathrm{ij}} / M_{\mathrm{j}}\right)
$$

where $K$ is a function of $m_{\mathrm{j}}, E_{\mathrm{l}}, m_{0}$ and $v$ which are respectively the mass of the $\mathbf{M}_{j}$ isotope, the energy spent to reach point $C$ (Fig. 4), the mass of $B$ and the velocity of $B$ before the last collision. For a head-on collision between $\mathrm{B}$ and $\mathrm{M}_{\mathrm{i}}$, one can easily calculate $K$ and verify that, in our conditions, $K$ has a negative sign. The isotopic deviation is then expressed by $\Delta_{\mathrm{ij}}=\left(a K / v_{\mathrm{c}}\right)\left(\delta \boldsymbol{M}_{\mathrm{ij}} / \boldsymbol{M}_{\mathrm{j}}\right)$.

This expression provides a qualitative but comprehensive explanation of the phenomena being observed : the parameter $a$ depends on the chemical bound between $A$ and $M_{j}$, thus the matrix effect can be described by the very different values, the parameter $a$ may take according to the nature of $\mathrm{A} ; K / v_{\mathrm{c}}$ is an increasing function of $E_{0}$, energy of secondary ions, and so is $\Delta_{\mathrm{ij}}$, one gets the energy effect. Moreover, for comparable values of $v_{\mathrm{c}}$, the smaller the parameter $a$, the higher the ionization probability. Thus, high ionization yields must be correlated with small isotopic deviations and a higher proportion of low energy ions, which is actually observed.

Of course, this interpretation is made on qualitative bases only. To go further would require an integration procedure on all exit pathways, all types of collisions (between $\mathrm{M}_{\mathrm{i}}$ and various $\mathrm{B}$ atoms), all possible values of parameter $a$ (including those corresponding to excited states), ... but one should have access to data concerning the angular and energy distributions of B atoms in motion in the target, the exact nature of $\mathrm{A}$ anions and the corresponding potential curves, the superficial oxygen (or fluorine) composition, ... It is worthwhile to note that if a superficial layer of different isotopic abundance is building up during a transition period, its influence should be negligible since we are working in the steady state in which the overall composition of the sputtered particles and that of the bulk material are necessarily the same.

4. Conclusion. - Although our results are preliminary, enough data have been gathered for characterizing the phenomena and setting up an interpretation based on a model which links isotopic and matrix effects on ionization yields together. Yet one must emphasize that the $\alpha$ values reported in this paper are liable to modifications depending upon the precision of the measurements and the experimental conditions (crystalline transparency of the target, nature, energy, angle of incidence of the primary ions, position and width of the energy pass-band for secondary ions...). Isotopic effects can certainly help to improve the understanding of ionization processes for positive ions as well as for negative ions, cluster ions or multicharged ions. This general remark could be extended to ionization processes differing from those described in this paper as those occurring when metals are bombarded with noble gas ions.
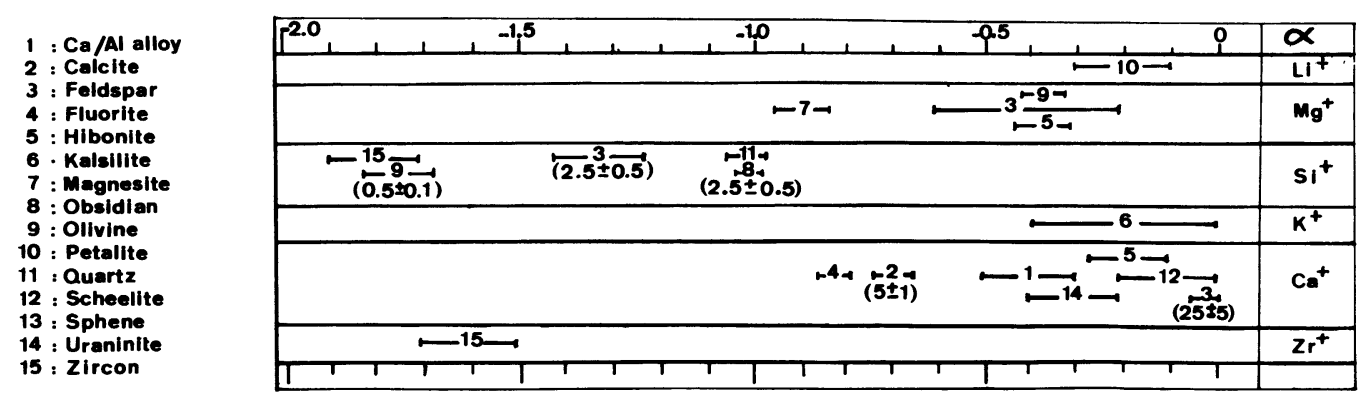

Fig. 5. - The $\tau$ values, inside brackets, are multiplied by $10^{4} ; \alpha$ and $\tau$ have been measured over a $0-20 \mathrm{eV}$ energy interval. 


\section{References}

[1] Havette, A. and Slodzian, G., C.R. Hebd. Séan. Acad. Sci. 290B (1980) 54 ; J. Physique Lett. 41 (1980) L-247.

[2] Slodzian, G. and Figuera, A., Proc. 8th Int. Conf. X-Ray Optics and Microanalysis, eds. D. Beaman, R. E. Ogilvie and D. Wittry (Midland Pendell, Michigan) 1980.

[3] Latanzaro, E. J. and MurPhy, T. J., J. Geophys. Res. 71 (1966) 1271-1274.
[4] Reynolds, J. and Verhoogen, Geochim.-Cosmochim. Acta 3 (1953) 224-234

[5] Russell, W. A., Papanastassiou, D. and Tombrello, T. A., Geochim.-Cosmochim. Acta 42 (1978) 1075-1080.

[6] Nikitin, E. E., Chemische Elementarprozesse, H. Hartmann, ed. (Springer-Verlag, Heidelberg) 1968. 